\title{
Hubungan antara Beban Kerja dan Kelelahan Kerja dengan Produktivitas Kerja Perawat di Ruang Rawat Inap Rumah Sakit Umum Bethesda GMIM Tomohon
}

\author{
Stivani S. Pantow \\ Grace D. Kandou \\ Paul A. T. Kawatu
}

\author{
Fakultas Kesehatan Masyarakat Unversitas Sam Ratulangi Manado \\ Email: pantowstivani@gmail.com
}

\begin{abstract}
Basically, productivity is influenced by three factors namely workload, work capacity, and additional burden due to work environment. Workload is usually associated with physical, mental, and social burdens. General Hospital Bethesda GMIM Tomohon provides services to patients with 123 nurses divided into several rooms. This study was aimed to determine the relationship between workload and work fatigue and work productivity of nurses in the Inpatient Room of the General Hospital Bethesda GMIM Tomohon. This was an observational analytical study using a cross sectional design. The sampling technique used Slovin formula and obtained 56 nurses as respondents. Data were analyzed by using the chi square test. The results showed that the relationship between workload and work productivity obtained a p-value of $0.001(\alpha=0.05)$, meanwhile the relationship between work fatigue and work productivity had a p-value of $0.001(\alpha=0.05)$. In conclusion, there was a significant relationship between workload and work productivity as well as between work fatigue and work productivity among the nurses of the Inpatient Room of Bethesda General Hospital, GMIM Tomohon.
\end{abstract}

Keywords: work productivity, work fatigue, workload

\begin{abstract}
Abstrak: Pada dasarnya produktivitas dipengaruhi oleh tiga faktor yaitu beban kerja, kapasitas kerja, dan beban tambahan akibat lingkungan kerja. Beban kerja biasanya berhubungan dengan beban fisik, mental maupun sosial yang memengaruhi tenaga kerja. RSU Bethesda GMIM Tomohon memberikan pelayanan pada pasien dengan jumlah perawat 123 orang yang dibagi dalam beberapa ruangan. Penelitian ini bertujuan untuk mengetahui adanya hubungan antara beban kerja dan kelelahan kerja dengan produktivitas kerja pada perawat di Ruang Rawat Inap RSU Bethesda GMIM Tomohon. Jenis penelitian ialah observasional analitik dengan desain potong lintang. Dengan menggunakan rumus Slovin didapatkan sebanyak 56 perawat sebagai responden. Analisis data menggunakan uji chi square. Hasil pengujian terhadap hubungan antara beban kerja dengan produktivitas kerja mendapatkan nilai $\mathrm{p}=0,001(\alpha=0,05)$. Hasil pengujian terhadap hubungan antara kelelahan kerja dengan produktivitas kerja mendapatkan nilai $\mathrm{p}=0,001(\alpha=0,05)$. Simpulan penelitian ini ialah terdapat hubungan antara beban kerja dan kelelahan kerja dengan produktivitas kerja pada perawat di Ruang Rawat Inap RSU Bethesda GMIM Tomohon.

Kata kunci: produktivitas kerja, kelelahan kerja, beban kerja
\end{abstract}

Kesehatan adalah faktor yang sangat penting dalam menunjang produktivitas tenaga kerja selaku sumber daya manusia. Kondisi kesehatan yang baik juga merupa- kan potensi untuk meraih produktivitas kerja yang baik. Kesehatan kerja diartikan sebagai ilmu kesehatan dan penerapannya yang juga bertujuan mewujudkan tenaga 
kerja yang sehat, produktif dalam bekerja, berada dalam keseimbangan yang mantap antara kapasitas kerja, beban kerja dan keadaan lingkungan kerja, serta terlindung dari penyakit yang disebabkan oleh pekerjaan dan lingkungan kerja. ${ }^{1}$

Data dari International Labour Organization (ILO) tahun 2013 menyebutkan bahwa setiap tahun sebanyak dua juta pekerja meninggal dunia karena kecelakaan kerja yang disebabkan oleh faktor kelelahan, ${ }^{2}$ sedangkan menurut Menteri Perindustrian MS Hidayat, produktivitas tenaga kerja Indonesia masih relatif rendah kalah dibandingkan dengan tiga negara kompetitor utama di ASEAN. Data produktivitas tahun 2013 menunjukkan bahwa produktivitas tenaga kerja Indonesia sebesar 9.500 dolar AS, dengan asumsi untuk Rp 11.000 per dolar AS, produktivitas tenaga kerja Indonesia setara Rp 104,5 juta per kerja per tahun. Angka produktivitas tenaga kerja Indonesia ini di bawah Singapura yang mencapai 92.000 dolar AS (1,012 miliar rupiah), Malaysia 33.300 dolar AS (363,3 juta rupiah), dan Thailand 15.400 dolar AS (169,4 juta rupiah). Bahkan, produktivitas tenaga kerja Indonesia berada di bawah rerata negara ASEAN yang sebesar 10.700 dolar AS (117,7 juta rupiah). ${ }^{3}$

Pada dasarnya produktivitas dipengaruhi oleh tiga faktor yaitu beban kerja, kapasitas kerja, dan beban tambahan akibat lingkungan kerja. Beban kerja biasanya berhubungan dengan beban fisik, mental maupun sosial yang memengaruhi tenaga kerja sedangkan kapasitas kerja berkaitan dengan kemampuan untuk menyelesaikan pekerjaan pada waktu tertentu. Beban tambahan akibat lingkungan kerja meliputi faktor fisik, kimia, dan faktor pada tenaga kerja sendiri yang meliputi faktor biologi, fisiologis, dan psikologis. ${ }^{4}$ Menurut Tarwaka, ${ }^{5}$ terdapat banyak faktor yang memengaruhi produktivitas kerja; salah satunya ialah kelelahan kerja. Kelelahan kerja secara langsung memengaruhi performa kerja. Terdapat kecenderungan bahwa tingkat performansi kerja seseorang yang tinggi disebut sebagai orang yang menunjukkan produktivitas yang tinggi. Namun sebaliknya seseorang yang tingkat performansi kerjanya tidak memenuhi kriteria perusahaan maka pekerja tersebut dikatakan mempunyai produktivitas yang rendah. ${ }^{5}$

Dari hasil wawancara awal di Rumah Sakit Umum Bethesda GMIM Tomohon, beberapa perawat mengalami keluhan sehingga mengakibatkan penurunan produktivitas kerja dalam melakukan pekerjaan, yaitu bekerja tidak sesuai dengan prosedur pekerjaan, tidak teliti dalam melaksanakan pekerjaan, datang terlambat, dan tidak semangat saat melakukan pekerjaan. Hal ini juga termasuk dalam gejala penurunan produktivitas kerja. Apabila gejala tersebut tidak segera diatasi maka akan memicu penurunan produktivitas kerja. Bila perawat mengalami penurunan produktivitas kerja, hal itu juga dapat memengaruhi kinerjanya. Berdasarkan uraian tersebut, peneliti tertarik untuk mengetahui apakah terdapat hubungan antara beban kerja dan kelelahan kerja dengan produktivitas kerja.

\section{METODE PENELITIAN}

Penelitian ini merupakan penelitian observasional analitik dengan menggunakan desain potong lintang. Penelitian dilaksanakan pada perawat di Ruang Rawat Inap Rumah Sakit Umum Bethesda GMIM Tomohon selama bulan September 2019. Populasi penelitian ialah 123 orang perawat di Ruang Rawat Inap Rumah Sakit Umum Bethesda GMIM Tomohon Responden yang digunakan dalam penelitian ini dihitung dengan menggunakan rumus Slovin dan mendapatkan 56 perawat.

\section{HASIL PENELITIAN}

Penelitian ini dilakukan terhadap 56 tenaga perawat di RSU Bethesda GMIM Tomohon yang terdiri atas 9 orang $(16,1 \%)$ laki-laki dan 47 orang $(83,9 \%)$ perempuan.

Tabel 1 memperlihatkan karakteristik usia tenaga perawat di RSU Bethesda GMIM Tomohon. Yang terbanyak ialah pada usia 26-35 tahun yaitu 16 orang $(28,6 \%)$ sedangkan yang paling sedikit ialah pada usia 56-64 tahun berjumlah 1 orang $(1,8 \%)$. 
Tabel 1. Distribusi responden berdasarkan usia

\begin{tabular}{ccc}
\hline Usia (tahun) & $\mathbf{N}$ & $\mathbf{\%}$ \\
\hline $17-25$ & 9 & 16,1 \\
$26-35$ & 16 & 28,6 \\
$36-45$ & 15 & 26,8 \\
$46-55$ & 15 & 26,8 \\
$56-65$ & 1 & 1,8 \\
Total & 56 & 100 \\
\hline
\end{tabular}

Tabel 2 menampilkan tingkat pendidikan perawat yaitu pendidikan SPK sebanyak 9 orang $(16,1 \%)$, pendidikan diploma sebanyak 42 orang $(75,0 \%)$ dan tingkat pendidikan S1 yaitu 5 orang $(8,9 \%)$.

Tabel 2. Distribusi responden berdasarkan tingkat pendidikan

\begin{tabular}{ccc}
\hline Tingkat Pendidikan & $\mathbf{N}$ & $\mathbf{\%}$ \\
\hline SPK & 12 & 21,4 \\
Diploma & 30 & 53,6 \\
S1 & 14 & 25 \\
Total & 56 & 100 \\
\hline
\end{tabular}

Tabel 3 mempelihatkan bahwa masa kerja perawat yang terbanyak ialah $\geq 5$ tahun tahun sebanyak 44 orang $(78,6 \%)$ dan yang yang paling sedikit ialah 1-2 tahun berjumlah 3 orang $(5,4 \%)$.

Tabel 3. Distribusi responden berdasarkan masa kerja

\begin{tabular}{ccc}
\hline Masa Kerja & N & \% \\
\hline $1-2$ tahun & 5 & 8,9 \\
$3-4$ tahun & 9 & 16,1 \\
$\geq 5$ tahun & 42 & 75 \\
Total & 56 & 100 \\
\hline
\end{tabular}

Hasil penelitian mendapatkan bahwa perawat yang mengalami beban kerja ringan yaitu 26 orang $(46,43 \%)$ dan yang mengalami beban kerja berat 30 orang $(52,63 \%)$. Selain itu, perawat yang mengalami kelelahan kerja sebanyak 22 orang $(39,29 \%)$ dan yang tidak mengalami kelelahan kerja yaitu 34 orang $(60,71 \%)$. Perawat yang memiliki produktivitas kerja tinggi sebanyak 29 orang $(51,8 \%)$, sedangkan yang memiliki produktivitas kerja rendah sebanyak 27 orang $(48,2 \%)$.

Tabel 4 menunjukkan bahwa perawat dengan produktivitas kerja tinggi yang memiliki beban kerja berat sebanyak 8 orang $(14,29 \%)$ dan beban kerja ringan sebanyak 22 orang $(39,29 \%)$. Perawat dengan produktivitas kerja rendah yang memiliki beban kerja berat sebanyak 21 orang $(37,5 \%)$ dan beban kerja ringan sebanyak 5 orang $(8,93 \%)$. Hasil uji chisquare mendapatkan nilai $\mathrm{p}=0,000<\alpha=0,05$, yang menyatakan bahwa terdapat hubungan antara beban kerja dengan produktivitas kerja pada perawat di RSU Bethesda GMIM Tomohon.

Tabel 5 menunjukkan bahwa perawat dengan produktivitas kerja tinggi yang mengalami kelelahan kerja sebanyak 5 orang $(8,93 \%)$ dan yang tidak mengalami kelelahan kerja sebanyak 24 orang $(42,86 \%)$. Perawat dengan produktivitas kerja rendah yang mengalami kelelahan kerja sebanyak 17 orang $(30,36)$, dan yang tidak mengalami kelelahan kerja sebanyak 10 orang $(17,86 \%)$. Hasil uji chi-square mendapatkan nilai $\mathrm{p}=0,001<\alpha=0,05$ yang menyatakan bahwa terdapat hubungan antara kelelahan kerja dengan produktivitas kerja perawat di RSU Bethesda GMIM Tomohon.

Tabel 4. Hasil analisis antara beban kerja dengan produktivitas kerja

\begin{tabular}{lccccccc}
\hline Beban kerja & \multicolumn{2}{c}{ Produktivitas kerja } & \multicolumn{2}{c}{ Total } & Nilai p \\
& \multicolumn{2}{c}{ Tinggi } & \multicolumn{2}{c}{ Rendah } & & & \\
& $\mathrm{N}$ & $\%$ & $\mathrm{~N}$ & $\%$ & $\mathrm{n}$ & $\%$ & \\
\hline Berat & 8 & $14,29 \%$ & 22 & $39,29 \%$ & 30 & $53,57 \%$ & \\
Ringan & 21 & $37,50 \%$ & 5 & $8,93 \%$ & 26 & $46,43 \%$ & 0,000 \\
Total & 29 & $51,79 \%$ & 27 & $48,21 \%$ & 56 & $100 \%$ & \\
\hline
\end{tabular}


Tabel 5. Hasil analisis antara kelelahan kerja dengan produktivitas kerja

\begin{tabular}{lccccccc}
\hline Kelelahan kerja & \multicolumn{2}{c}{ Produktivitas kerja } & \multicolumn{2}{c}{ Total } & Nilai p \\
& \multicolumn{2}{c}{ Tinggi } & \multicolumn{2}{c}{ Rendah } & & & \\
& $\mathrm{N}$ & $\%$ & $\mathrm{~N}$ & $\%$ & $\mathrm{n}$ & $\%$ & \\
\hline Mengalami & 5 & $8,93 \%$ & 17 & $30,36 \%$ & 22 & $39,29 \%$ & \\
Tidak mengalami & 24 & $42,86 \%$ & 10 & $17,86 \%$ & 34 & $60,71 \%$ & 0,001 \\
Total & 29 & $51,79 \%$ & 27 & $48,21 \%$ & 56 & $100 \%$ & \\
\hline
\end{tabular}

\section{BAHASAN}

Pada penelitian ini, usia responden dikelompokan menjadi 5 kategori yaitu 17 25 tahun, 26-35 tahun, 36-45 tahun, 46-55 tahun, 56-64 tahun. Responden terbanyak terdapat pada kategori usia 26-35 tahun yaitu 16 orang $(28,6 \%)$, diikuti oleh kategori usia 36-45 tahun sama banyaknya dengan kategori usia 46-55 tahun yaitu masing-masing berjumlah 15 orang $(26,8 \%)$, kategori usia $17-25$ tahun terdapat 9 orang $(16,1 \%)$, dan kategori usia 56-65 tahun sebanyak 1 orang $(1,8 \%)$ (Tabel 1). Perawat yang berusia muda tentu dapat lebih cepat dalam melakukan suatu pekerjaan dibandingkan dengan perawat yang usianya sudah tua namun pengalaman perawat berusia tua lebih banyak. Hasil penelitian yang dilakukan oleh Wowor et $\mathrm{al}^{6}$ menyatakan tidak terdapat hubungan antara usia dengan produktivitas kerja pada perawat di RSUD Noongan $(\mathrm{p}=0,255)$.

Berdasarkan karakteristik jenis kelamin terdapat 56 responden yang terdiri dari 47 responden $(83,9 \%)$ yang berjenis kelamin perempuan dan 9 responden $(16,1 \%)$ berjenis kelamin laki-laki dengan tingkat pendidikan terbanyak yaitu pada responden yang tingkat pendidikan Diploma sebanyak 30 orang $(56,6 \%)$, S1 sebanyak 14 orang $(25 \%)$, dan SPK sebanyak 12 orang $(21,4 \%$ ) (Tabel 2). Perawat yang berjenis kelamin laki-laki tentu memiliki tenaga atau kekuatan fisik yang lebih dibandingkan perempuan namun dalam hal tertentu perempuan lebih teliti dibandingkan laki-laki. Untuk menghasilkan kinerja yang sesuai harus ada pembagian tugas antara laki-laki dan perempuan.

Masa kerja petugas perawat dibagi menjadi tiga kategori yaitu kategori baru (12 tahun), sedang (3-4 tahun), dan kategori lama ( $\geq 5$ tahun). Sebanyak 3 perawat memiliki masa kerja selama 1-2 tahun sedangkan perawat dengan masa kerja 3-4 tahun yaitu 9 orang dan untuk masa kerja selama $\geq 5$ tahun sebanyak 44 perawat (Tabel 3). Perawat di RSU Bethesda yang memiliki masa kerja lebih dari 5 tahun (75\%) mempunyai pengalaman yang lebih dibandingkan dengan pekerja yang masa kerjanya kurang dari 5 tahun. Pekerja akan lebih berdaya atau mampu disebabkan oleh peningkatan pengalaman yaitu dalam hal masa kerja. Dengan bertambahnya masa kerja maka pekerja akan semakin berkembang dan menguasai pekerjaan. ${ }^{7}$

Berdasarkan hasil penelitian yang dilakukan dengan menggunakan kuesioner terhadap perawat di Rumah Sakit Umum Bethesda GMIM Tomohon, diketahui bahwa yang memiliki beban kerja berat sebanyak 30 orang $(52,63 \%)$, sedangkan untuk beban kerja ringan yaitu 26 orang $(46,43 \%)$. Beban kerja perawat di RSU Bethesda Tomohon ialah menyiapkan kebutuhan pasien, masalah kesehatan pasien termasuk memantau dan memelihara kondisi pasien, mengikuti pertemuan berkala yang diadakan kepala ruangan, menyusun rencana keperawatan, juga menyiapkan pasien yang akan pulang. Oleh karena masih kurangnya jumlah perawat maka tingkat kesulitan dalam bekerja menangani pasien masih sering terjadi sehingga perawat mengalami beban kerja yang termasuk dalam faktor eksternal beban kerja; hal ini yang menjadi beban di rumah sakit tersebut. Setiap beban kerja yang diterima oleh seseorang harus sesuai atau seimbang baik terhadap kemampuan fisik, kemampuan kognitif maupun ketebatasan manusia yang menerima beban tersebut. ${ }^{8}$ 
Hasil penelitian menunjukkan bahwa kelelahan kerja yang dialami oleh responden yaitu dari 56 perawat terdapat 22 orang $(39,29 \%)$ mengalami kelelahan kerja sedangkan yang tidak mengalami kelelahan sebanyak 34 orang $(60,71 \%)$. Gejala kelelahan yang sering dialami oleh responden ialah merasa haus dan merasa berat di kaki; kelelahan kerja tersebut disebabkan karena melaksanakan asuhan keperawatan. Jika tenaga kerja telah mulai merasa lelah dan tetap dipaksa untuk terus bekerja, kelelahan akan semakin bertambah. Kondisi lelah demikian sangat menggangu kelancaran pekerjaan dan juga berefek buruk kepada tenaga kerja itu sendiri. ${ }^{1}$

Hasil penelitian ini mendapatkan bahwa perawat yang memiliki produktivitas kerja tinggi sebanyak 29 orang $(51,8 \%)$, sedangkan yang memiliki produktivitas kerja rendah sebanyak 27 orang $(48,2 \%)$. Berdasarkan hasil yang didapat di lapangan kerja perawat, yang mengakibatkan penurunan produktivitas kerja perawat yaitu jam perawatan pasien per hari, jumlah pertemuan atau kontak dengan pasien, dan masih ada juga perawat yang sering datang terlambat sehingga menurunkan performa kinerja.

Berdasarkan hasil yang didapat, perawat dengan produktivitas kerja tinggi yang memiliki beban kerja berat sebanyak 8 orang $(14,29 \%)$ sedangkan yang beban kerja ringan sebanyak 21 orang $(37,50 \%)$. Perawat dengan produktivitas kerja rendah yang memiliki beban kerja berat sebanyak 22 orang $(39,29 \%)$ sedangkan yang beban kerja ringan sebanyak 5 orang $(8,93 \%)$. Hasil uji chi-square menunjukkan bahwa terdapat hubungan bermakna antara beban kerja dengan produktivitas kerja pada perawat di RSU Bethesda GMIM Tomohon ( $\mathrm{p}=0,001$ $<\alpha=0,05$ ) (Tabel 4). Hasil penelitian ini sejalan dengan penelitian yang dilakukan oleh Minarsih ${ }^{9}$ yang juga menggunakan uji chi-square dan mendapatkan adanya hubungan bermakna antara beban kerja dengan produktivitas kerja perawat $(\mathrm{p}=0,000)$.

Berdasarkan hasil penelitian didapatkan bahwa perawat dengan produktivitas kerja tinggi yang mengalami kelelahan kerja sebanyak 5 orang $(8,93 \%)$ sedangkan yang tidak mengalami kelelahan kerja sebanyak 24 orang $(42,86 \%)$. Perawat dengan produktivitas kerja rendah yang mengalami kelelahan kerja sebanyak 17 orang $(30,36)$ sedangkan yang tidak mengalami kelelahan kerja sebanyak 10 orang $(17,86 \%)$. Dari hasil penelitian ini dapat dilihat bahwa perawat yang tidak mengalami kelelahan memiliki produktivitas yang lebih tinggi dibanding perawat yang mengalami kelelahan. Hasil uji chi-squere menunjukkan bahwa terdapat hubungan bermakna antara kelelahan kerja dengan produktivitas kerja perawat di RSU Bethesda GMIM Tomohon $(\mathrm{p}=0,001<\alpha=0,05)$ (Tabel 5). Hasil penelitian ini sejalan dengan penelitian yang dilakukan oleh Verawati ${ }^{10}$ yaitu dengan hasil pengujian menggunakan koefisien kontingensi mendapatkan nilai asosiasi sebesar 0,798 berada pada rentang nilai $0,50-0,75$ yang berarti memiliki tingkat hubungan sedang. Hal ini menunjukkan bahwa terdapat hubungan antara kelelahan kerja dengan produktivitas tenaga kerja.

\section{SIMPULAN}

Berdasarkan hasil penelitian ini dapat disimpulkan bahwa terdapat hubungan antara beban kerja dan kelelahan kerja dengan produktivitas kerja pada perawat di Ruang Rawat Inap Rumah Sakit Umum Bethesda GMIM Tomohon.

Bagi Rumah Sakit Umum Bethesda Tomohon disarankan untuk mengatasi kelelahan kerja serta beban kerja perawat agar perawat selalu produktif dalam mengerjakan tugas dan tanggung jawabnya. Bagi perawat RSU Bethesda Tomohon disarankan untuk lebih efektif dalam menyesuaikan diri dengan tugas dan tanggung jawab yang diberikan agar tingkat produktivitas selalu terjaga. Selain itu perawat perlu menciptakan kerjasama antara teman kerja untuk mewujudkan kondisi kerja yang baik dan menyenangkan agar beban kerja berkurang.

\section{DAFTAR PUSTAKA}

1. Suma'mur PK. Higiene Perusahaan dan Keselamatan Kerja (HIPERKES). Jakarta: Sagung Seto, 2014. 
2. International Labor Organization. Tren Ketenagakerjaan dan Sosial di Indonesia 2013 Memperkuat peran pekerjaan layak dalam kesetaraan pertumbuhan. Jakarta: ILO, 2013.

3. Hidayat T. Stres dalam lingkup pekerjaan. Jurnal Indon Psychiat. 1998;XXXI(3).

4. Depkes RI Direktorat Jenderal Pembinaan Kesehatan Masyarakat. Upaya Kesehatan Kerja Sektor Informal di Indonesia. Jakarta: Departemen Kesehatan Republik Indonesia, 1990.

5. Tarwaka. Ergonomi untuk Keselamatan Kesehatan Kerja dan Produktivitas Kerja (Cetakan Pertama). Surakarta: Uniba Press, 2004.

6. Wowor T, Pinontoan O, Akili R. Hubungan antara umur, kelelahan dengan produktivitas kerja pada perawat di Rumah Sakit Umum Daerah Noongan Kecamatan Langowan Barat Kabupaten
Minahasa tahun 2016. Media Kesehatan. 2017;8(2):1-7.

7. Fitriantoro AR. Hubungan antara usia dan masa kerja dengan kinerja dosen [Skripsi]. Yogyakarta: Universitas Sanata Dharma; 2009.

8. Tarwaka. Ergonomi Industri. Surakarta: Harapan Press, 2015.

9. Minasih M. 2011. Hubungan beban kerja perawat dengan produktivitas kerja perawat di IRNA non bedah (penyakit dalam) RSUP Dr. M. Djamil Padang. Available from: URI: http://repo. unand.ac.id/id/eprint/217

10. Verawati L. Hubungan tingkat kelelahan subjektif dengan produktivitas pada tenaga kerja bagian pengemasan di CV Sumber Barokah. The Indonesian Journal of Occupational Safety and Health. 2016;5(1):51-60. 